\title{
Perishability, dynamic pricing and price discrimination: evidence from flower markets in Bogotá*
}

\author{
Santiago Ortiz ${ }^{\dagger} \quad$ Geraldine Castelblanco $^{\ddagger} \quad$ César Mantilla ${ }^{\S}$
}

November 3, 2020

\begin{abstract}
Perishable products traded in informal markets might be subject to price variations in two opposite directions. Whereas the absence of posted prices opens the door for price discrimination based on some buyers' attributes, the reduction in quality over time might decrease prices to secure a transaction. We use an audit experiment to detect these pricing patterns in the informal flower markets nearby the cemeteries of Bogotá, Colombia. We analyze 441 price quotations. We interpret the lower prices in the afternoon than in the morning as evidence of dynamic pricing. Regarding price discrimination, we find that women are quoted a higher price than men, whereas attire (formal versus informal) does not affect prices. The price variations associated with the time of the day and the gender of the buyer appear to be independent of each other.
\end{abstract}

Keywords: audit study; dual labor markets; informal markets;

JEL Classification Codes: J46, Q56

\footnotetext{
*Financial Support from the program "Inclusión productiva y social: programas y politicas para la promoción de una economía formal, código 60185, que conforma la Alianza EFI, bajo el Contrato de Recuperación Contingente No. FP44842220-2018." is gratefully acknowledged. Field assistance from María Camila Andrade, Paula Cortés, Kevin Galarcio, María Alejandra Pava, Alejandro Preciado and Felipe Rincón was of invaluable help. Authors' contributions: all authors contributed to the experimental design, analysis of data and writing the paper. SO and GC directed the data collection process.

${ }^{\dagger}$ Department of Economics, Universidad del Rosario. e-mail: santiago.ortizo@urosario.edu.co

$\ddagger$ Department of Economics, Universidad del Rosario. e-mail: geraldine.castelbl01@urosario.edu.co

$\S$ Department of Economics, Universidad del Rosario. Address: Calle 12C \# 4-69, Bogotá, Colombia. e-mail: cesar.mantilla@urosario.edu.co
} 


\section{Introduction}

Transactions in informal markets, prevalent in low- and middle-income countries -LMICs hereafter-, are seldom subject to the relative bargaining power of buyers and sellers. For perishable goods, two forces affect this bargaining power in opposite directions. On the one hand, informal markets foster the absence of posted prices, increasing seller's discretionary power Grossman and Honig. 2017). On the other hand, perishability is associated to a reduction in quality over time, reducing the profit margin that sellers can keep from a transaction, thus reducing their discretionary power with respect to final consumers or intermediaries (Thuy et al., 2019).

The trade of such perishable goods in large quantities led to the development of specific mechanisms. A good example is the descending-price Dutch auction, named after the Aalsmeer flower auction in the Netherlands, whose purpose is to increase the speed at which trades occur due to the nature of the good (Van den Berg et al., 2001; Katok and Kwasnica, 2008). Recent developments include optimal dynamic pricing models for perishable goods, which take into account inventory levels and competitors (Zhao and Zheng, 2000: Sweeting, 2012; Gallego and Hu, 2014).

Informal retailers in LMICs do not fully profit from such mechanisms for several reasons. First, traded quantities are relatively low, and they largely depend on physical buyer-seller interactions. Second, storage costs of natural perishable goods may be high for informal retailers, reducing the scope for optimal inventory management. Third, informal retailers lack full access to credit markets (La Porta and Shleifer, 2014: Wellalage and Locke, 2016), increasing their risk exposure to not selling their product before it must be wasted.

We argue and provide evidence that informal flower retailers in Bogotá adopt simpler dynamic pricing strategies. The main question of this study is to understand whether this dynamic pricing interplays with price discrimination. Think, for instance, that sellers may infer that there are two "types" of buyers, and one of these types has better knowledge about the reduction in quality associated with the perishability of the good. As a result, dynamic pricing strategies become typedependent, yielding evidence of statistical discrimination (Arrow, 1973; Fang and Moro, 2011).

To explore the interaction between dynamic pricing and price discrimination, we conduct an audit study with 441 interactions with flower vendors located in the vicinity of three cemeteries in Bogotá. To detect dynamic pricing, the auditors, acting as potential sellers, visited the cemeteries in the morning and the afternoon. We investigate whether there was price discrimination based on gender, by including four female and four male auditors into the study; and whether there was price discrimination based on inferred wealth, by changing how the auditor was dressed when visiting the flower stands.

The exploration of the flower market nearby a cemetery gives us two advantages for tackling 
our question. First, flowers in stands located nearby the cemeteries are typically bought to bring to the graves. Therefore, there is a popular flower arrangement that can be bought in most flower stands, and it serves as a homogeneous good to be quoted from multiple sellers. This could have been more difficult with other flower markets located elsewhere in the city. Second, although the seller tend to have an informational advantage regarding the good's dynamic quality, this advantage can be reduced in the case of flower stands near a cemetery. We perform the audits on Sundays, the day of the week when most people visit the graves of their beloved ones. This day serves as an implicit coordination device, maximizing the chance that flowers have been restocked within the past 24 to 36 hours, making prices within a time frame and between flower stands more homogeneous.

Two additional advantages of performing the audit on Sundays are that flowers are fresh, making us more likely to observe the maximum prices; and that since this is the busiest day, it is less likely that vendors remind the faces of the auditors.

We find that quoted prices are lower in the afternoon than in the morning, a pattern that we interpret as evidence of dynamic pricing. Regarding price discrimination, we find that women are quoted a higher price than men, whereas attire does not play any significant role in the quoted prices. Although we expected that the price variation decreased in the afternoon, the dynamic pricing and the higher prices charged to women appear to operate independently.

Perishable products impose some deviations from more efficient and competitive markets. Wohlgenant (2001) analyzes the link between retail, wholesale and point-of-shipment prices for a group of fresh vegetables, concluding that an asymmetric price transmission is very likely in perishable markets. Retailers refuse to increase the price of perishable products requiring high turnover due to the fear of possible reductions in sales and increases in the incidence of spoilage. Similarly, Jensen (2007) argues that the fear of losing products due to waste for spoilage prevents the adoption of competitive pricing strategies along the supply chain. However, the patterns at the end of the supply chain might differ. The introduction of technologies, not necessarily for storage, can alleviate these inefficiencies. Jensen (2007) shows that, before to the mobile phone network entry in Kerala (India), fish markets in this area had more price dispersion and the market did not clear, leading to resource waste. On the other hand, there is evidence for a supermarket chain in Colombia that perishable goods have less rigidity and more adjustment in daily prices and a lower mark-up, compared to non-perishable goods (Giulietti et al., 2020).

Our results also relate to the literature examining price discrimination employing audit studies. There is non-experimental evidence for a perishable good, fish in the Fulton Market (NY), revealing that Asian buyers are charged on average 6.3 cents per pound less than white buyers (Graddy, 2006). The explanation is that Asian buyers are more elastic since they resell to estab- 
lishments located in poorer neighborhoods. Regarding experimental evidence, it is vast for labor and housing markets (Riach and Rich, 2002, Flage, 2018) and is expanding for other markets functioning as online platforms (Besbris et al. 2015; Cui et al., 2020). The evidence is more scarce for LMICs, where audit studies have shed some clues on compliance on the healthcare sector (Currie et al., 2014: Das et al., 2016), gender differences in bargaining behavior (Castillo et al., 2013), and class discrimination in informal trade (Grossman and Honig, 2017).

We contribute by setting up an audit study with a perishable good in an LMIC. Its relevance dwells in the fact that, in the absence of optimal storage and inventory capabilities, informal sellers are subject to tighter constraints for entering into dynamic pricing strategies that may interplay with price discrimination.

The rest of the paper goes as follows. Section 2 provides a general context of the informal flower markets in Bogotá, our study site. Section 3 describes in detail how and where we implement the audits. Sections 4 and 5 report and offer a discussion of our results, respectively. Section 6 concludes.

\section{The flower markets in Bogotá}

Colombia is the second-largest exporter of flowers in the World, renowned for the quality of crops and the diversity of export destinations ${ }^{1}$ However, about twenty percent of the flower production remains in the country and is marketed through different mechanisms, including small distributors that typically operate in informal markets. Informality is commonly associated to either street-vending or non-compliance to the rules governing business activity (e.g., payment of taxes and social security contributions) $4^{2}$ In the case of flower vendors, the "informal" status comes from the latter condition since they were relocated to publicly funded commercial galleries two decades ago $3^{3}$

The flower market is pertinent for experimentation, as the price of a particular flower arrangement is determined through very short face-to-face negotiations. We focus on the flower vendors located in the galleries next to three cemeteries in Bogotá. The most popular gallery is located in the vicinity of the cemeteries in the Northern area of Bogotá. Approximately 20 years ago, about sixty street vendors were relocated from the AutoNorte Highway Bay to 198th Street. Vendors

\footnotetext{
${ }^{1}$ https://procolombia.co/node/1255

2 https://colaboracion.dnp.gov.co/CDT/Conpes/Economicos/3956.pdf

${ }^{3}$ Local administrations in Bogotá, our study site, have sought to implement various policies to recover the public space, generating controversies among the involved actors (Donovan, 2008). Consequently, flower vendors were relocated, mostly to commercial galleries funded by the Institute for Social Economy - IPES. IPES is responsible for offering income generation alternatives to the population in the informal economy, exercising its activities in the public space.
} 
in this gallery, one of the largest flower sales complexes, claim their sales dramatically fell after this relocation. The explanation provided by the vendors is that the new location increased the transaction costs of buyers, who have to stray from the highway and enter the complex.

The flower markets are usually open from 9 a.m. to 6 p.m. on weekdays and from 5 a.m. to 6 p.m. on weekends. Most sales occur on Sunday morning in our three audited locations, the day that cemeteries receive more visits. Depending on the daily sales, some flower vendors stay for longer periods of time, expecting to have some additional transactions. According to the vendors' experience, they may end up a whole journey without any sale. However, they typically wait because a last-minute order, paid in advance for future delivery, can provide some earnings for the day. On less busy days, flower vendors also work on the maintenance and cleaning gravestones in the cemetery under informal monthly contracts with recurrent clients.

As an additional feature worth mentioning, most of the flower stands are family businesses. Some of the elderly sellers have been in this business for thirty years. They have gradually expanded and linked more family members, as some type of inheritance to younger family members. As a consequence, different flower stands in the same area are served by members of the same family.

\section{Methods and data}

\subsection{Audit sites}

The choice of vendors close to cemeteries obeys a methodological constraint. A potential difficulty of inquiring about perishable goods in an audit study is to control for the dynamic quality of the good, for which the vendor would have better information than the buyer. If auditors are not aware of the delivery dates of a perishable good, some unobserved heterogeneities might result confounded with the price variations intended to exploit. We aim to overcome this obstacle by exploiting the fact that bringing flowers to the dead is an extended tradition in Colombia, and visitors tend to pay these visits on holydays, usually Sundays. Hence, even if we do not know about the delivery dates of flowers, it is plausible that their quality is the highest on the day in which visits to the cemetery are at its maximum. In other words, the expected peak of visits on Sundays acts as a coordination mechanism that decreases the between-vendors variation in the quality of a perishable good at the time of our audit.

We selected three clusters of flower vendors in Bogotá, each located in the vicinity of a cemetery. The three clusters were geographically sparse, exploiting the associated socioeconomic differences of the city. One cluster in the Northern area, nearby two cemeteries associated with medium 
and high socioeconomic status; one cluster nearby the city's downtown, or Central area; and one cluster in the Southern area. The latter two clusters are associated with low socioeconomic status (see the map in Figure A.1 in the Appendix for more details).

The number of flower stands varies across the three clusters. There were approximately 50 stands in the Northern cluster, followed by the Southern cluster with 40 stands. The smaller one was the Central cluster, with 15 stands. The stands were relatively close to each other. In all three clusters, the vendors were approximately two meters apart. However, in some cases, there is a large distance between two audited stores in the Central Cemetery. This because some intermediate stores were empty. For this reason, in these cases, the vendors were approximately six or eight meters apart.

We made an initial visit to the three cemeteries to identify a popular floral arrangement that was available in most of the flower stands. We selected a small arrangement of white roses with green leaves that we quoted during the audit visits. The large amount of sellers in each cluster, added to the quotation of a similar flower arrangement serving as a homogeneous good, suggests that differences in quotations will obey to dynamic pricing and discrimination patterns.

\subsection{Implementation of the audits}

The audit study was executed during two weekends, one in mid-June and one in mid-July, in 2019 4 Eight experimenters, four men and four women, played the role of auditors or potential buyers in all the three cemeteries. Following Castillo et al. (2013), we hypothesize that vendors could react to two characteristics when quoting differential prices: gender and attire. The latter is interpreted as a signal of social class, potentially reflecting a higher willingness to pay.

To vary the attire while holding other characteristics of the auditor constant, each auditor visited the same location twice, in the morning, from 8:00 to 10:00 a.m.; and in the afternoon, from 3:00 to 5:00 p.m. Half of the auditors wore casual attire in the morning and formal attire in the afternoon (see Figure A.2 in the Appendix). For counter-balancing, the other half of auditors started with formal attire and then switched. Women with formal attire wore a dark coat, dark trousers, dark glasses, and make-up. Women with casual attire wore jeans, sneakers, and did not wear make-up. Men with formal attire wore trousers, long-sleeved shirts inside the trousers, formal shoes, and dark belt. Men with casual attire wore jeans, sneakers, a polo shirt or a striking sweater, a cap, and dark glasses. Moreover, men had short hair and were clean shaved. We arrived walking at the cluster areas $\sqrt[5]{5}$ We thus have three controlled dimensions in our audits: time

\footnotetext{
${ }^{4}$ We avoided the weekends in-between because the celebration of Father's day could alter prices.

${ }^{5}$ Arriving by car might generate diverse sources of price discrimination associated with inferred wealth that we cannot control with our experimental design.
} 
of the day, allowing us to detect dynamic pricing strategies; and gender and attire, allowing us to examine whether the dynamic pricing is differential on these characteristics.

In each flower stand, the auditor approached the vendor and asked for the specific flower arrangement's price. We will call it the initial price. After hearing this price, the auditor asked for a discount. Specifically, the auditor asked for a minimum price at which the vendor was willing to sell the flower arrangement, a common practice in informal markets. Regardless of whether a discount was given or not, we call this second observation the final price. We might lose some control in the analysis of final prices, compared to initial prices, Nonetheless, final prices might be useful as they may reflect some differences in bargaining abilities between men and women. The auditor moved away from the stand to an inconspicuous place once she obtained the quotation of the flower arrangement, where she noted both prices. Moreover, the auditor collected information on each vendor's two visible characteristics: sex, and whether he/she looked as being more or less than 30 years old. All this information was collected in the cellphone of the auditor, who acted as if she was writing a text message while being careful not to raise any suspicion about the audits.

The auditors were instructed to visit vendors that were separated by at least two flower stands. In this way, we minimize the chances that one vendor in our sample observes the interaction with another vendor, increasing the plausibility for treating our observations as independent (Zamora et al. 2019). One can imagine that, if a neighboring vendor observes this "failed" transaction, she may update her beliefs about the buyer's bargaining abilities and alter the quoted price.

More importantly, since the auditor visited each flower gallery in the morning and the afternoon, she did not visited the same stands. This procedure allows us to make the visits to contiguous flower stands less suspicious. However, by not visiting the same stands, a caveat from our data collection strategy is that we cannot perform a within-vendors analysis of discrimination.

\subsection{Data}

We describe the summary statistics of the 441 interactions carried out in the three flower galleries. Table 1 reports information for the initial and final quoted prices for the whole sample, as well as the price ratio (Panel A). It also reports the differences for the initial price and the price ratio between time of the day (Panel B) and the location of the flower galleries, grouped by socioeconomic status (Panel C).

Panel A in Table 1 reveals an average initial price, $P_{1}$, of 6,210 COP (std. dev. 960), roughly 2 USD by the time the audit experiment was conducted. The low standard deviation of this price reveals the expected homogeneity. We also observe that, on average, vendors offer a $10 \%$ discount with respect to the initially quoted price. Figure 1 gives some additional information regarding 
Table 1: Descriptive statistics: Quoted prices in Colombian pesos

\begin{tabular}{|c|c|c|c|c|c|c|}
\hline & Obs & Mean & Std. Dev & Median & Max & Min \\
\hline \multicolumn{7}{|l|}{ Panel A: aggregate data } \\
\hline Initial price $\left(P_{1}\right)$ & 411 & $6,210.8$ & 959.8 & 6,000 & 10,000 & 4,000 \\
\hline Final price $\left(P_{2}\right)$ & 411 & $5,577.5$ & 875.8 & 5,500 & 10,000 & 4,000 \\
\hline Price ratio $\left(P_{2} / P_{1}\right)$ & 411 & 0.902 & 0.086 & 0.857 & 1 & 0.667 \\
\hline \multicolumn{7}{|c|}{ Panel B: by time of the day } \\
\hline$P_{1}$ Morning & 241 & $6,327.8$ & 937.8 & 6,000 & 10,000 & 4,000 \\
\hline$P_{1}$ Afternoon & 200 & 6,070 & 969.4 & 6,000 & 9,000 & 4,000 \\
\hline$P_{2} / P_{1}$ Morning & 241 & 0.901 & 0.085 & 0.857 & 1 & 0.667 \\
\hline$P_{2} / P_{1}$ Afternoon & 200 & 0.903 & 0.087 & 0.857 & 1 & 0.714 \\
\hline \multicolumn{7}{|l|}{ Panel C: by location } \\
\hline$P_{1}$ North & 179 & $6,284.9$ & 949.4 & 6,000 & 10,000 & 5,000 \\
\hline$P_{1}$ South + Center & 262 & $6,160.3$ & 965.4 & 6,000 & 9,000 & 4,000 \\
\hline$P_{2} / P_{1}$ North & 179 & 0.908 & 0.086 & 0.857 & 1 & 0.714 \\
\hline$P_{2} / P_{1}$ South + Center & 262 & 0.897 & 0.085 & 0.857 & 1 & 0.667 \\
\hline
\end{tabular}

quoted prices. The left panel (a) shows that initial prices were typically quoted in multiples of 1,000 COP. Nonetheless, prices in multiples of 500 COP become more common in the afternoons. The right panel $(b)$, on the other hand, reveals that the average $10 \%$ discount comes from a bimodal distribution: a null discount and a 15\% discount (presumably reducing the price from 6,000 to 5,000) are observed equally often.

Panel B in Table 1 reveals the number of interactions both in the morning (241) and in the afternoon (200). The average mean $P_{1}$ quoted in the morning was around 6,327 COP, while in the afternoon there was a reduction in $P_{1}$, roughly $257 \mathrm{COP}$, equivalent to a decrease of $4 \%$. We did not find a difference between the discounts offered in the morning and the afternoon. Panel $\mathrm{C}$ in Table 1 disaggregated information by location according to the socioeconomic location in which each cemetery is located. In this Table, we group the Southern and Center clusters, which are located in low-income areas. We found that the average initial price $\left(P_{1}\right)$ quoted in the Northern area is weakly higher than the $P_{1}$ quoted in the Southern-Central area. However, this is not statistically significant. In both clusters, the median discount is around $15 \%$ and the average discount is $10 \%$.

Table 2 describes the collected vendors' characteristics. We observe that in almost four out of every five interactions, the vendor was a woman. This proportion was particularly large in the 


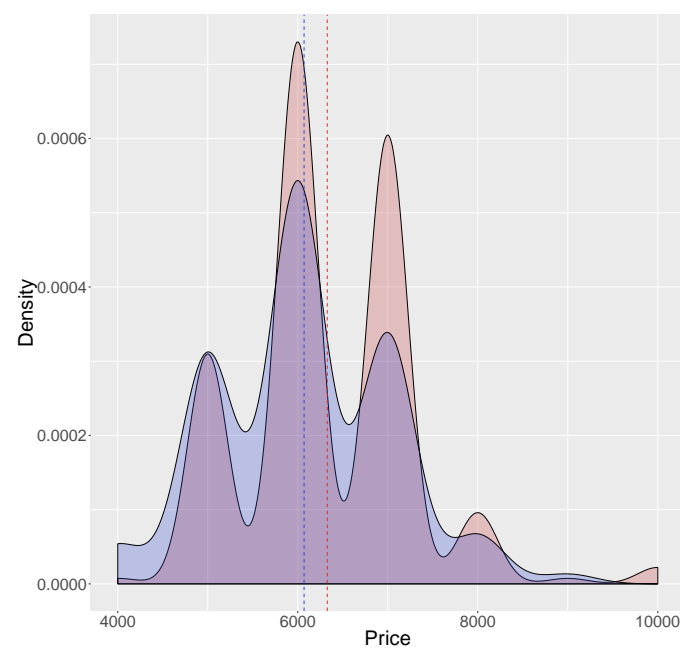

(a) Initial price $P_{1}$

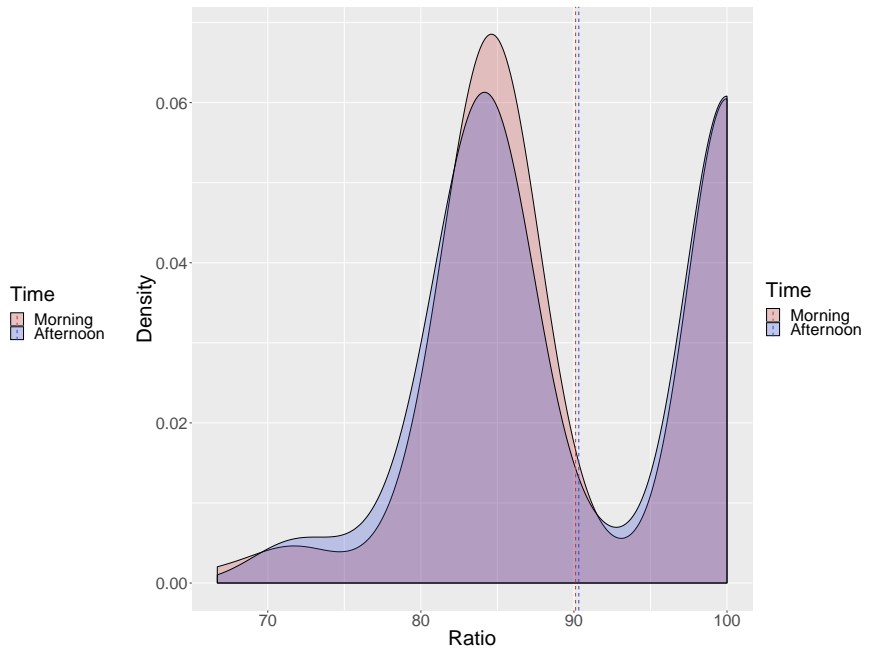

(b) Ratio $\frac{P_{2}}{P_{1}}$

Figure 1: Distributions of price quotations

Table 2: Vendors' observed and inferred characteristics (by flower gallery)

\begin{tabular}{lrrrr} 
& South & North & Center & Total \\
\hline Man & $50(27.6 \%)$ & $40(22.3 \%)$ & $4(4.9 \%)$ & $94(21.3 \%)$ \\
Woman & $131(72.4 \%)$ & $139(77.7 \%)$ & $77(95.1 \%)$ & $347(78.7 \%)$ \\
& & & & \\
Perceived age $\geq 30$ & $116(64.1 \%)$ & $143(79.9 \%)$ & $81(100 \%)$ & $340(77.1 \%)$ \\
Perceived age $<30$ & $65(35.9 \%)$ & $36(20.1 \%)$ & $0(0 \%)$ & $101(22.9 \%)$ \\
\hline
\end{tabular}

flower gallery located in Bogota's Center. We observed that more than $70 \%$ of the interactions were made by sellers with a perceived age greater than 30 years. Particularly at the cluster in the Center, we did not identify any seller with a perceived age lower than 30 years.

\section{Results}

The central motivation is to understand whether dynamic pricing interplays with price discrimination in the flower market, given the perishability of this good. We propose the following linear regression model to answer this question:

$$
\text { Price }_{i j k}=\beta_{0}+\beta_{1} \text { Afternoon }_{i j k}+\beta_{2} \text { Women }_{i k}+\beta_{3} \text { Formal }_{i k}+\delta T_{i j k}+\lambda_{k}+\gamma_{i}+\epsilon_{i j k}
$$


The dependent variable is the price of a floral arrangement quoted by the seller $j$ to the potential buyer $i$ in the cemetery $k$. As for the explanatory variables, Afternoon defines whether the vendor-buyer interaction took place in the morning (0) or the afternoon (1); Woman is a categorical variable capturing the buyer's sex; Formal takes the value of one when the buyer was in formal attire, and zero otherwise. In addition, $T_{j k}$ is a vector including vendor characteristics (sex, perceived age, and week of the year in which the audit took place), and the parameters $\lambda_{k}$ and $\gamma_{i}$ capture cemetery and auditor fixed effects, respectively.

Table 3 reports the effects of the variables of interest on the initial quoted price. We observe that the average quoted price in the afternoon is between 219 and 242 COP lower than in the morning, or about $4 \%$. We interpret this result as evidence of dynamic pricing in the flower market, associated with the good's perishability. Regarding the buyer's sex, we find that women were quoted a price 335 COP higher than men. By contrast, we do not find statistically significant evidence of price discrimination based on wearing formal or casual attire by the time of the price quotation.

In models (3) and (4), we augment the model shown above, including interaction terms between Afternoon and the variables Woman and Formal. We do not find evidence that price discrimination against women increases in the afternoon. On the other hand, the large coefficient for the interaction term between Afternoon and Formal, which offsets the coefficient for Afternoon, suggests that the price reduction observed in the afternoon applies to buyers in casual attires. Nonetheless, given the lack of precision of the estimated interaction variable, our evidence in this direction is not conclusive. In the best case scenario, it seems to be a strategy adopted only by a share of vendors, but it is not a systematic pattern.

We conduct the same exercise with the final (discounted) quoted price. The results are similar to those reported in Table 3 prices are lower in the afternoon, and women are charged a higher price. Since the results are qualitative identical to those for the initial price, and unobserved characteristics might influence discounted prices, we relegate these results to the Appendix (see Table A.1).

We report below a different exercise with the price ratio as a dependent variable. Unlike our previous results, the price ratio might reveal whether vendors inferred any difference in bargaining abilities that might interplay either with the dynamic pricing or the discrimination patterns after quoting a reduced price. As in the case of final prices, discounts might reflect unobserved characteristics and results must be interpreted with caution. Nonetheless, Table 4 reveals that the offered discounts are not explained by any of our three variables of interest.

We conducted an additional exercise to check whether the additional price charged to female auditors depends on its interaction with a male or female vendor. Recall from Table 2 that roughly three out of every four vendors are women. Hence, if there are any differences related to gender- 
Table 3: Dynamic pricing and the effect of buyer's attributes (gender and attire) on the initial price

\begin{tabular}{lcccc}
\hline & $(1)$ & $(2)$ & $(3)$ & $(4)$ \\
& Initial price & Initial price & $\begin{array}{c}(1 \text { Initial price } \\
\text { Initial price }\end{array}$ \\
\hline Afternoon & $-242.8^{* * *}$ & $-219.2^{* * *}$ & $-239.9^{* *}$ & $-483.3^{*}$ \\
& $(91.87)$ & $(77.26)$ & $(115.0)$ & $(267.7)$ \\
Woman & -44.06 & $334.9^{* *}$ & $319.3^{* *}$ & $591.9^{* *}$ \\
& $(90.13)$ & $(143.0)$ & $(158.9)$ & $(288.3)$ \\
Formal & 70.85 & 53.74 & 51.14 & -207.4 \\
& $(91.75)$ & $(78.70)$ & $(78.17)$ & $(265.6)$ \\
Woman $\times$ Afternoon & & & 41.52 & \\
& & & $(151.9)$ & \\
Formal $\times$ Afternoon & & & & 510.9 \\
& & & & $(493.6)$ \\
Constant & $6667.0^{* * *}$ & $5297.1^{* * *}$ & $5307.7^{* * *}$ & $5571.8^{* * *}$ \\
& $(142.0)$ & $(188.2)$ & $(194.7)$ & $(330.0)$ \\
\hline Observations & 441 & 441 & 441 & 441 \\
R-squared & 0.044 & 0.315 & 0.315 & 0.316 \\
Adjusted R-squared & 0.033 & 0.294 & 0.292 & 0.293 \\
\hline Auditors FE & & $\checkmark$ & $\checkmark$ & $\checkmark$ \\
Wave FE & & $\checkmark$ & $\checkmark$ & $\checkmark$ \\
Cemeteries FE & & $\checkmark$ & $\checkmark$ & $\checkmark$ \\
\hline
\end{tabular}

Notes: ${ }^{*} p<.1,{ }^{* *} p<.05,{ }^{* * *} p<.01$ Robust standard errors in parentheses.

All regressions are controlled by seller characteristics: seller gender and seller perceived age.

Wave fixed effects correspond to the days the audit experiment was carried out.

specific interactions, they might be concealed in our previous regressions.

Table 5 confirms that this is not the case. The interaction between a female vendor and a female auditor is negative but not statistically significant. Moreover, we did not find any statistically significant evidence suggesting that woman vendors quoted a higher initial price in the afternoon. These results support the larger price charged to female auditors originally reported in Table 3 .

\section{Discussion}

We find robust evidence of a decrease in quoted prices within the day. We argue that this result evidences a dynamic pricing strategy from flower vendors. A reader fully aware of the context of 
Table 4: Dynamic pricing and the effect of buyer's attributes (gender and attire) on the price ratio

\begin{tabular}{lcccc}
\hline & $(1)$ & $(2)$ & $(3)$ & $(4)$ \\
& Ratio & Ratio & Ratio & Ratio \\
\hline Afternoon & -0.000217 & 0.00205 & -0.00737 & -0.0202 \\
& $(0.00813)$ & $(0.00778)$ & $(0.0110)$ & $(0.0330)$ \\
Woman & -0.0129 & -0.00652 & -0.0136 & 0.0151 \\
& $(0.00806)$ & $(0.0157)$ & $(0.0162)$ & $(0.0346)$ \\
Formal & -0.00244 & -0.00251 & -0.00369 & -0.0245 \\
& $(0.00822)$ & $(0.00791)$ & $(0.00805)$ & $(0.0322)$ \\
Woman $\times$ Afternoon & & & 0.0189 & \\
& & & $(0.0158)$ & \\
Formal $\times$ Afternoon & & & & 0.0430 \\
& & & & $(0.0619)$ \\
Constant & & & & \\
& $0.862^{* * *}$ & $0.918^{* * *}$ & $0.923^{* * *}$ & $0.941^{* * *}$ \\
\hline Observations & $(0.0120)$ & $(0.0194)$ & $(0.0197)$ & $(0.0380)$ \\
R-squared & 441 & 441 & 441 & 441 \\
Adjusted R-squared & 0.058 & 0.176 & 0.179 & 0.177 \\
\hline Auditors FE & 0.047 & 0.151 & 0.152 & 0.150 \\
\hline Wave FE & & $\checkmark$ & $\checkmark$ & $\checkmark$ \\
Cemeteries FE & & $\checkmark$ & $\checkmark$ & $\checkmark$ \\
\hline Note: $p<.1 * *<$ & $\checkmark$ & $\checkmark$ & $\checkmark$ \\
\hline
\end{tabular}

Notes: ${ }^{*} p<.1{ }^{* *} p<.05,{ }^{* * *} p<.01$ Robust standard errors in parentheses. All regressions are controlled by seller characteristics: seller gender and seller perceived age. Wave fixed effects correspond to the days the audit experiment was carried out.

informal workers in developing countries may argue that this price reduction is rather an evidence of the need to secure a transaction to guarantee a minimum of daily profits. We argue that this situation would better reflect the pricing patterns during weekdays, but not on Sundays, given the large influx of buyers.

Regarding price discrimination, one of our hypotheses was based on the formal attire of a potential buyer in the flower market. We anticipated a higher price charged to buyers who wore formal attires since they appear to have a higher social status and therefore, greater availability to pay (Grossman and Honig, 2017). However, we did not find evidence about price discrimination lead by attire differences. We conjecture that the absence of an effect is due to a different signal transmitted by formal attires: flower sellers can interpret this attire as a signal of a tradition of 
Table 5: Effect of the interaction between seller's and auditors gender on the initial price

\begin{tabular}{lcccc}
\hline & \multicolumn{2}{c}{$(1)$} & \multicolumn{2}{c}{$(2)$} \\
& \multicolumn{2}{c}{ Initial price } & \multicolumn{2}{c}{ Initial price } \\
\hline Afternoon & $-218.3^{* * *}$ & $(77.38)$ & $-371.8^{*}$ & $(196.9)$ \\
Female auditor & $444.7^{* *}$ & $(191.3)$ & $425.1^{* *}$ & $(202.3)$ \\
Formal & 53.82 & $(78.71)$ & 52.36 & $(78.22)$ \\
Female vendor $\times$ Female auditor & -152.2 & $(196.2)$ & -150.9 & $(197.6)$ \\
Female auditor $\times$ Afternoon & & & 40.93 & $(152.1)$ \\
Female vendor $\times$ Afternoon & & & 167.1 & $(198.0)$ \\
Constant & $5236.0^{* * *}$ & $(218.6)$ & $5293.2^{* * *}$ & $(238.7)$ \\
\hline Observations & \multicolumn{2}{c}{441} & \multicolumn{2}{c}{441} \\
R-squared & \multicolumn{2}{c}{0.316} & \multicolumn{2}{c}{0.317} \\
Adjusted R-squared & \multicolumn{2}{c}{0.293} & \multicolumn{2}{c}{0.291} \\
\hline Auditors FE & \multicolumn{2}{c}{$\checkmark$} & \multicolumn{2}{c}{$\checkmark$} \\
Wave FE & \multicolumn{2}{c}{$\checkmark$} & \multicolumn{2}{c}{$\checkmark$} \\
Cemeteries FE & \multicolumn{2}{c}{$\checkmark$} & \multicolumn{2}{c}{$\checkmark$} \\
\hline
\end{tabular}

Notes: ${ }^{*} p<.1{ }^{* *} p<.05,{ }^{* * *} p<.01$ Robust standard errors in parentheses.

All regressions are controlled by seller characteristics: seller gender and seller perceived age. Wave fixed effects correspond to the days the audit experiment was carried out. We conducted a third model with a triple interaction (Woman $\times$ Woman seller $\times$ Afternoon). We did not get any statistical significance in this estimator. Results are available upon request.

respect. Thus, it is not necessarily related to a higher willingness to pay.

By contrast, we find that the initial price quoted to women is around 320 COP higher than the price quoted to men. An evident question at this point is what drives the price difference. One might consider the usual suspect, taste-based discrimination. Nonetheless, engaging with this type of discrimination is costly (Szymanski, 2000; Fershtman and Gneezy, 2001), and the costs could be even higher for flower vendors with a low and fluctuating daily wage: a foregone sale may imply a lower profit in the future, given the perishability of flowers.

We thus conjecture that more complex mechanisms drive the higher price quoted to women auditors. We believe that this higher price results from vendors' expectations of a higher demand for quality. Flower vendors, interviewed after the audit experiment was over, claimed that women are more likely to bring flowers to the dead compared to men. A direct implication is that women have more experience in the flower market, and this experience translates into a better ability to request flower arrangements that look fresher and aesthetically satisfactory, two signals of quality. If vendors anticipate these requests, their best-response is to offer to the potential woman buyer 
a higher-quality flower arrangement that might be slightly more costly. Despite we devote some time to look for a common flower arrangement, expecting that it will be treated as a homogeneous good, it is still possible that both vendors and experienced buyers detect some heterogeneity. Thus, we argue that the price differential is a quality premium.

The interaction between the variables capturing dynamic pricing and price discrimination does not reveal any effect. We anticipated a decrease in the price charged to women in the afternoon due to the product's perishable effect, which would cause the premium for quality to disappear. However, our estimations reveal that the higher prices charged to women do not vary with the time of the day. More generally, one may imagine that dynamic pricing behavior will dominate discriminatory patterns as the quality of the good decreases. Nonetheless, they appear to operate as independent mechanisms. The lack of evidence for more complex discrimination patterns in informal markets is consistent with Zamora et al. (2019).

\section{Conclusions}

Our audit experiment sought to understand how dynamic pricing interplays with price discrimination in a market for perishable goods. We aimed at detecting whether flower vendors quoted lower prices on Sunday afternoon compared to the same day in the morning, and whether prices also vary according to the auditor's gender and attire. More importantly, we were interested in the interactions between the price reduction due to the perishability of flowers and the "types" of buyers that may evoke the buyer's sex and dress.

We quoted prices for a small arrangement of white roses with green leaves in three areas of Bogotá with variation in socioeconomic status. In each area, there was a flower gallery next to a cemetery. Four women and four men acted as auditors, wearing different attires and visiting two cemeteries during each journey of data collection. Audits were conducted on Sundays, the busiest day in these galleries, to ensure that the offered flowers were fresh, locating us at the early stage of the dynamic pricing pattern.

We find price reductions in the afternoon, compared to the morning, that we interpret as evidence of dynamic pricing in the informal flower market. We also evidence larger prices quoted to women. We offered a conjecture on why this pattern might reflect statistical rather than tastebased discrimination: even if we employ a widespread and homogeneous flower arrangement, vendors may anticipate an expected higher quality on the arrangements bought by women. On the other hand, we do not find any interplay between the dynamic pricing pattern and the prices offered to women.

Flowers bought nearby cemeteries were methodologically useful for the audit study. They 
provided us with a common and (relatively) homogeneous good to quote, the buyer would not directly consume it, and there was an implicit coordination based on the day of the week that guaranteed a similar restocking pattern among vendors.

An important question is how these results may extrapolate to other perishable products traded in informal markets. We have two considerations in mind. First, price discrimination based on gender appears to be related to differences in quality in goods that are assumed to be relatively homogeneous. If vendors correctly anticipate that different buyer types may have different willingness to pay for aesthetic-related attributes, the absence of posted prices and the associated discretionary power of sellers may actually contribute to reducing the waste or perishable products. Think, for instance, that food waste due to the aesthetic appearance of products (Halloran et al. 2014) can be reduced in informal markets by reducing the price of fruits and vegetables that might look rare. This consideration must be taken with a grain of salt since the suggested mechanisms for the observed price discrimination are speculative.

Second, the lack of adequate storage capabilities for informal vendors implies that most of the risk of perishability resides in a vulnerable and widespread sector of the population in LMICs. The observed price reduction during the afternoon reveals that this population is foregoing gains to secure a purchase. Further research may explore if the foregone gains are equivalent to a willingness to pay for collectively improving storage capabilities.

\section{References}

Arrow, K. (1973). The theory of discrimination, discrimination in labor markets. Achenfelter, A. Ress (eds.), Princeton-New Jersey.

Besbris, M., Faber, J. W., Rich, P., and Sharkey, P. (2015). Effect of neighborhood stigma on economic transactions. Proceedings of the National Academy of Sciences, 112(16):4994-4998.

Castillo, M., Petrie, R., Torero, M., and Vesterlund, L. (2013). Gender differences in bargaining outcomes: A field experiment on discrimination. Journal of Public Economics, 99:35-48.

Cui, R., Li, J., and Zhang, D. J. (2020). Reducing discrimination with reviews in the sharing economy: Evidence from field experiments on Airbnb. Management Science, 66(3):1071-1094.

Currie, J., Lin, W., and Meng, J. (2014). Addressing antibiotic abuse in China: an experimental audit study. Journal of Development Economics, 110:39-51.

Das, J., Holla, A., Mohpal, A., and Muralidharan, K. (2016). Quality and accountability in health 
care delivery: audit-study evidence from primary care in India. American Economic Review, 106(12):3765-99.

Donovan, M. (2008). Informal cities and the contestation of public space: The case of Bogota's street vendors, 1988 2003. Urban Studies, 45:29-51.

Fang, H. and Moro, A. (2011). Theories of statistical discrimination and affirmative action: A survey. In Handbook of social economics, volume 1, pages 133-200. Elsevier.

Fershtman, C. and Gneezy, U. (2001). Discrimination in a segmented society: An experimental approach. The Quarterly Journal of Economics, 116:351-377.

Flage, A. (2018). Ethnic and gender discrimination in the rental housing market: Evidence from a meta-analysis of correspondence tests, 2006-2017. Journal of Housing Economics, 41:251-273.

Gallego, G. and Hu, M. (2014). Dynamic pricing of perishable assets under competition. Management Science, 60(5):1241-1259.

Giulietti, M., Otero, J., and Waterson, M. (2020). Rigidities and adjustments of daily prices to costs: Evidence from supermarket data. Journal of Economic Dynamics and Control, 116:7-8.

Graddy, K. (2006). Markets: the Fulton fish market. Journal of Economic Perspectives, 20(2):207-220.

Grossman, S. and Honig, D. (2017). Evidence from Lagos on Discrimination across Ethnic and Class Identities in Informal Trade. World Development, 96(C):520-528.

Halloran, A., Clement, J., Kornum, N., Bucatariu, C., and Magid, J. (2014). Addressing food waste reduction in Denmark. Food Policy, 49:294-301.

Jensen, R. (2007). The digital provide: Information (technology), market performance, and welfare in the South Indian fisheries sector. The Quarterly Journal of Economics, 122(3):879-924.

Katok, E. and Kwasnica, A. M. (2008). Time is money: The effect of clock speed on seller's revenue in Dutch auctions. Experimental Economics, 11(4):344-357.

La Porta, R. and Shleifer, A. (2014). Informality and development. Journal of Economic Perspectives, 28(3):109-26.

Riach, P. A. and Rich, J. (2002). Field experiments of discrimination in the market place. The Economic Journal, 112(483):F480-F518. 
Sweeting, A. (2012). Dynamic pricing behavior in perishable goods markets: Evidence from secondary markets for Major League Baseball tickets. Journal of Political Economy, 120(6):1133-1172.

Szymanski, S. (2000). A market test for discrimination in the English professional soccer leagues. Journal of Political Economy, 108(3):590-603.

Thuy, P. T. T., Flaaten, O., and Skonhoft, A. (2019). Middlemen: good for resources and fishermen? Environment and Development Economics, 24(5):437-456.

Van den Berg, G. J., Van Ours, J. C., and Pradhan, M. P. (2001). The declining price anomaly in Dutch rose auctions. American Economic Review, 91(4):1055-1062.

Wellalage, N. H. and Locke, S. (2016). Informality and credit constraints: evidence from SubSaharan African MSEs. Applied Economics, 48(29):2756-2770.

Wohlgenant, M. (2001). Handbook of Agricultural Economics, volume 1, chapter 16, pages 934-970. Elsevier.

Zamora, P., Mantilla, C., and Blanco, M. (2019). Price discrimination in informal labor markets in Bogotá: An audit experiment during the 2018 FIFA World Cup. SocArXiv 6r5hf, Center for Open Science.

Zhao, W. and Zheng, Y.-S. (2000). Optimal dynamic pricing for perishable assets with nonhomogeneous demand. Management Science, 46(3):375-388. 


\section{A Appendix}

\section{A.1 Script for experimenters}

The script says:

Good morning/afternoon, how are you? I am quoting a small rose arrangement. Do you have any one?

Seller answers "Yes" or "No". [If the seller answers "Yes" then the dialogue continues, otherwise it ends].

What is the price of this arrangement?

[Subject should indicate the arrangement most similar to the one already determined as a guide]. Seller gives a price.

And how much would be the minimum to buy it?

Seller gives a price.

Thank you very much, have a nice day. 


\section{A.2 Additional Tables and Figures}

Table A.1: Effect of buyer's attributes (gender and attire) on final price

\begin{tabular}{lcccc}
\hline & $(1)$ & $(2)$ & $(3)$ & $(4)$ \\
& Discounted price & Discounted price & Discounted price & Discounted price \\
\hline Woman & -134.0 & $248.7^{*}$ & 186.8 & $640.4^{* *}$ \\
& $(82.64)$ & $(138.7)$ & $(151.0)$ & $(314.8)$ \\
Afternoon & $-233.2^{* * *}$ & $-199.2^{* * *}$ & $-282.0^{* *}$ & $-601.8^{* *}$ \\
Formal & $(83.85)$ & $(74.92)$ & $(110.2)$ & $(297.4)$ \\
& 44.80 & 27.55 & 17.18 & -370.3 \\
Woman $\times$ Afternoon & $(84.64)$ & $(76.18)$ & $(76.65)$ & $(297.1)$ \\
& & & 165.6 & \\
Formal $\times$ Afternoon & & & $(150.4)$ & 778.5 \\
& & & & $(561.7)$ \\
Constant & & & & $5273.9^{* * *}$ \\
& $5766.9^{* * *}$ & $4855.4^{* * *}$ & $4897.7^{* * *}$ & $(356.3)$ \\
\hline Observations & $(144.3)$ & $(188.6)$ & $(196.9)$ & 441 \\
R-squared & 441 & 441 & 441 & 0.224 \\
Adjusted R-squared & 0.025 & 0.221 & 0.223 & 0.199 \\
\hline Auditors FE & 0.013 & 0.198 & 0.198 & $\checkmark$ \\
Wave FE & & $\checkmark$ & $\checkmark$ & $\checkmark$ \\
Cemeteries FE & & $\checkmark$ & $\checkmark$ & $\checkmark$ \\
\hline
\end{tabular}

Notes: ${ }^{*} p<.1{ }^{* *} p<.05,{ }^{* * *} p<.01$ Robust standard errors in parentheses.

All regressions are controlled by seller characteristics: seller gender and seller perceived age. Wave fixed effects correspond to the days the audit experiment was carried out. 
Figure A.1: Location of cemeteries - Bogotá (Colombia)

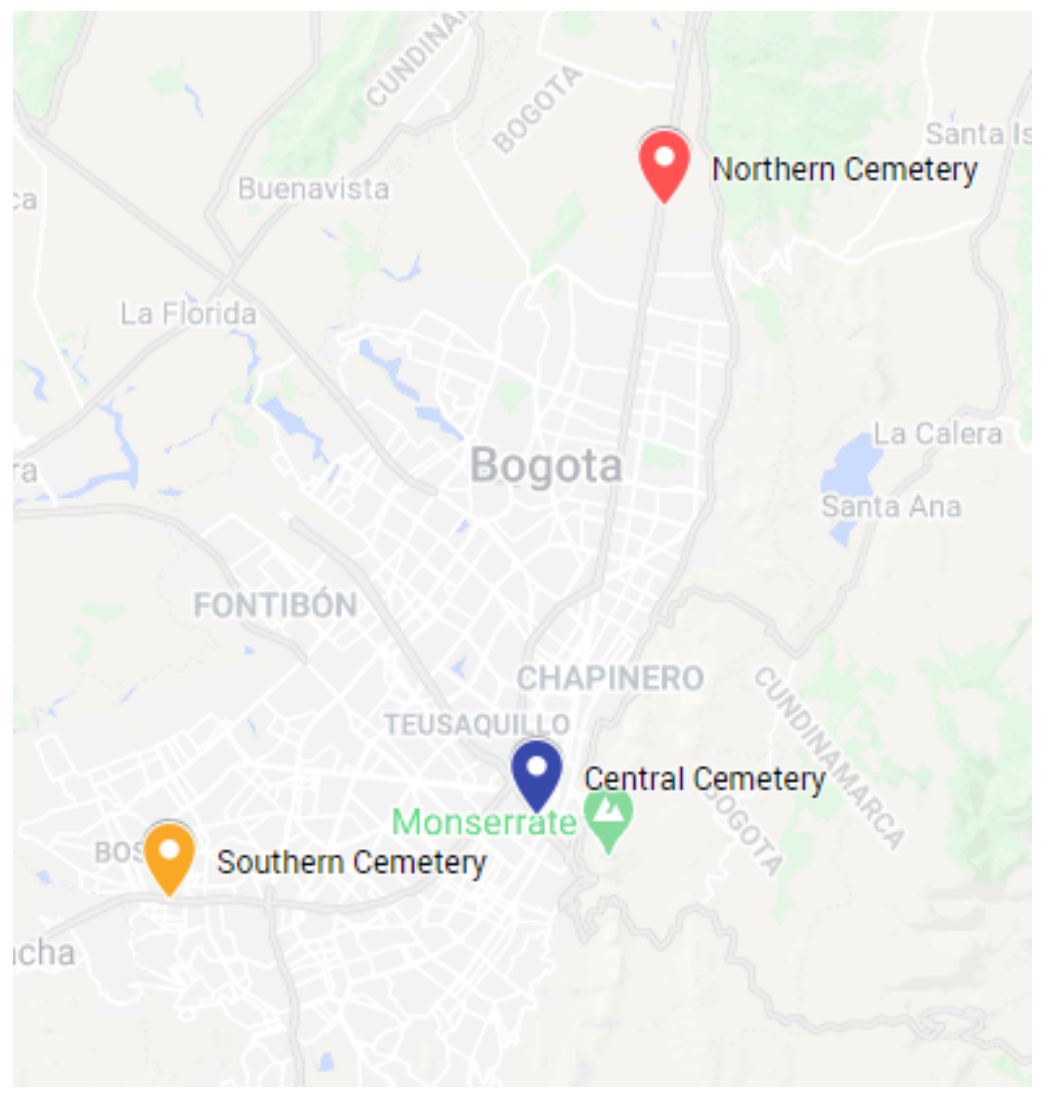


Figure A.2: Appearance of auditors

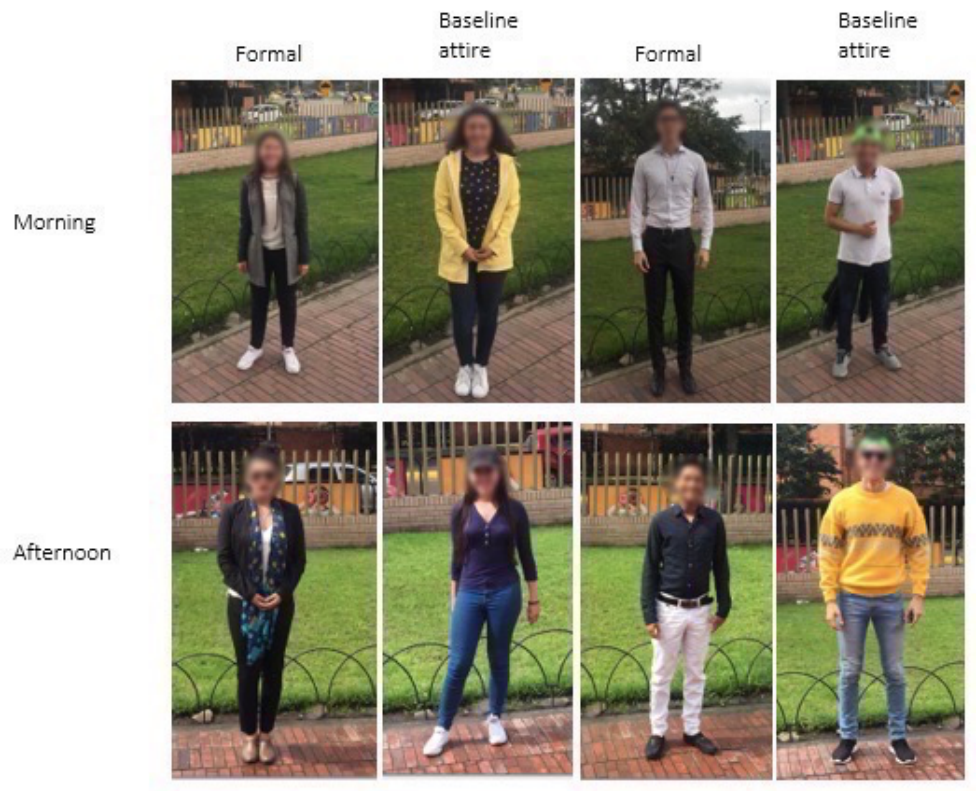

(a) Wave 1
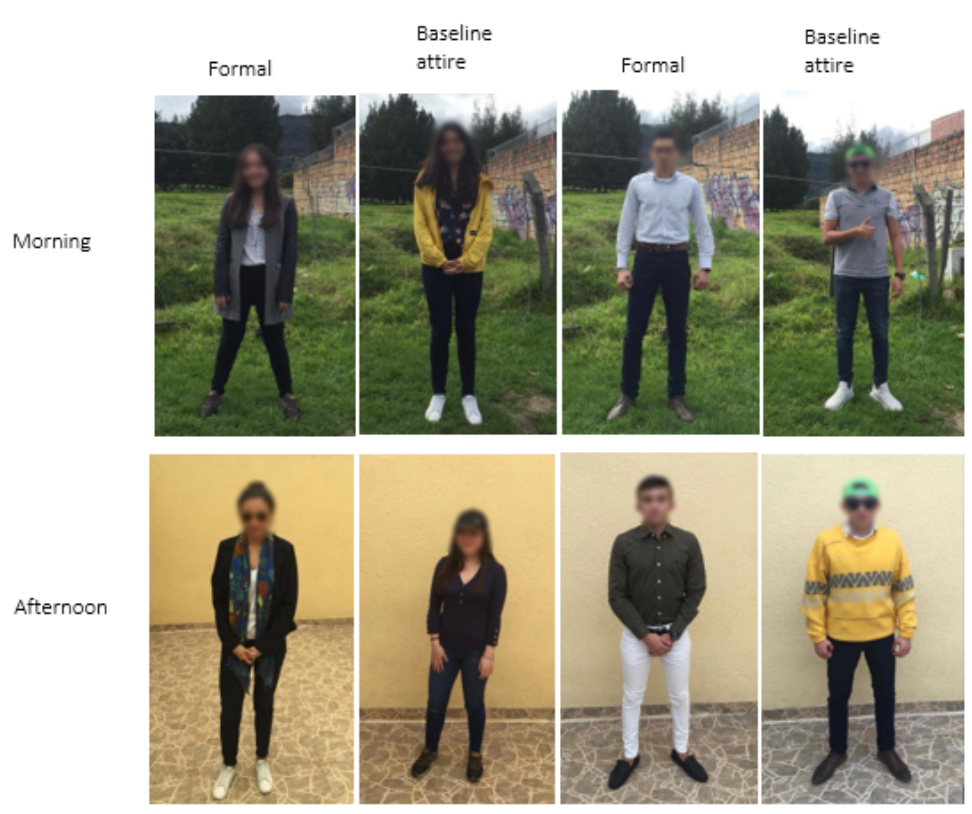

(b) Wave 2 